\title{
Interactive comment on "Organic carbon in surface sediments of the North Sea and Skagerrak" by Markus Diesing et al.
}

\section{Anonymous Referee \#1}

Received and published: 26 October 2020

General comments The study takes stock of organic carbon sequestered in surface sediments $(0-10 \mathrm{~cm})$ of the North Sea and Norwegian Trough/Skagerrak, and extrapolates sparse (and regionally extremely clustered) sedimentation rate records based on $210 \mathrm{~Pb}$ to estimate annual organic carbon accumulation. Based on these existing data (analyses over the last decades), it applies sophisticated upscaling approaches and extensive error estimates, based on data from the EEZs of the UK and Norway. Using a suite of potential predictor variables (distance from shore, water depth, gridded sediment properties, numerical hydrodynamic model, etc), the main depocenter of the entire North Sea is (again) found to be the Skagerrak. Although this is hardly news (cited papers by Eisma, van Weering and de Haas and others), this is the first published, rigorous and statistically elaborate examination of $C$ stocks and burial rates

Printer-friendly version

Discussion paper 
in the entire shelf sea environment. What is new is the estimates of errors, and this is relevant as an incentive for further dedicated ground-truthing work. Although the manuscript offers essentially no surprises, because the resulting estimates of stocks and accumulation rates are close to previous estimates, the intrinsic motivation on the other hand is more interesting and potentially far-reaching. This is because the data are discussed in context of carbon accounting: A case is made for including substantial sedimentary carbon stocks in surface sediments, which greatly exceed other "blue carbon" stocks, into national carbon management accounts. This in turn raises some intriguing questions in a high-energy shelf sea environment such as the North Sea, where lateral transports of fine sediment fractions and associated organic carbon spiraling feeds accumulation remote from the production sites, and where erosion exhumes old carbon from a large, international catchment. How will this carbon sequestration be partitioned into national shares and accounted for? Will the credits go to the country that provides the storage space, or to the countries that provide nutrients for production of biological material? These accounting questions are clearly not at the focus here, but are highly relevant and offer potential for conflict. They should at least be pointed out. The manuscript is well structured, written and illustrated. It is very explicit on technical terms and concepts of data processing, which are probably beyond the expertise of most readers. I for one have to simply trust that the very elaborate approach is appropriate for the purpose, superior to more simple statistic procedures, and that results are correct. As stated above, the explicit elaboration on errors of the analysis is welcome, as are suggestions on how to reduce these errors.

Specific comments Some questions pertaining to the data base(s): Why have only data from the UK and Norway been analysed, although there must be significant stores of data from other countries? Have the authors checked the OSPAR data bases, or PANGEA for easily accessible data sets? To fill data gaps, the authors employed a technique of placing "pseudo observations" (Hengl et al., 2017 are cited as a reference). Did the authors just say: "We need a data point here - let's make it $0.1 \mathrm{wt} \%$ organic carbon and $0 \mathrm{~cm} / \mathrm{yr}$ sedimentation rate"? This needs to be explained in more

Printer-friendly version

Discussion paper
Interactive comment 
detail. Although not explicitly stated, the most important predictors emerging from the analysis are rather intuitive and straightforward (judging from Figure 6): bathymetry, oxygen penetration depth, and energy at the sea floor. Also, OC density and accumulation rates are included as predictors - but aren't these two the parameters to be estimated? The physical predictors are but a few of a long list of parameters that have gone into the analysis (in Table 1). Of these important (there is no measure of statistical impact given for any of them) predictors, bathymetry and energy at the seafloor are not independent (orbital velocities), and the way that oxygen penetration depths are calculated (as a function of mud content) makes one wonder, if they are not linked to bathymetry and energy at the seafloor as well. Instead, one would have expected that $\mathrm{OC}$ accumulation and $\mathrm{OC}$ standing stock are linked to grain size, for which spatially explicit data sets are available (e.g., Bockelmann et al., 2017) - was there no statistic relationship? If oxygen penetration depth is indeed a function of mud content, why is not mud content the logical predictor? What is the depth of oxygen penetration calculated by the empirical formula used here in the first place? This important piece of information is shown in Fig. 6, but eyeballing the box-and-whisker plot for the turnover zone in the figure and the profiles given in Lohse et al. (1996) suggest to me that the formula used here overestimates the oxygen penetration depth. This will not make much difference in the overall conclusion that not much carbon is stored anywhere except the Norwegian Trough and Skagerrak, but then oxygen penetration depth is probably not a good predictor of OCAR and OC density, because animals influence that depth. There are much more elaborate (model-based) and spatially contiguous estimates for oxygen penetration depths available at least in the southern North Sea (e.g., Luff and Moll, 2004; Pätsch et al., 2018, and probably more recent ones as well), and it might be advisable to use such data instead of the (apparently upublished) empirical relationships used that may be only regionally applicable. Finally, Zhang et al. (2019) highlight the important role of macrozoobenthos in recycling (and preserving) organic carbon at the sediment-water interface in much of the southern North Sea, an aspect not addressed in the present manuscript. An important issue of course is the origin

Printer-friendly version

Discussion paper
Interactive comment

\section{3}


of OC, stated as an open question in the suggestions for future research. In general, the discussion on why some parts of the sea floor do and others do not accumulate organic carbon (section 6.2) implies that in-situ production and processing dictate $\mathrm{OC}$ density and OCAR. Resuspension and transport, and associated exposure to progressive degradation are not discussed. But why then do the hydrodynamic predictors (M2 current and orbital velocity) apparently have such a strong influence? Fine-grained sediment and associated OC buried in the Skagerrak and Norwegian Trough comprise input from rivers, atmospheric input, coastal and sea floor erosion, and primary production that feed into suspended and bed load transport of the North Sea. There are data sets on $\mathrm{C} / \mathrm{N}$ ratios and even delta13C (see for example the thesis by de Haas, Geologica Ultraiectina 155,1997 ), which indicate that about $20 \%$ is of terrigenous origin, and an unspecified source is erosion of older strata. Mineralisation in these muds only affects that (relatively small) portion supplied by production in the surface layer (see papers on oxygen consumption measurements by Lohse, Helder, Rysgaard etc., ). Finally, the manuscripts advocates and discusses at some length whether marine protected areas should be established to prevent accumulated organic carbon from being resuspended and remineralised. The manuscript cites an astounding estimate of potential damages arising from mineralisation caused by demersal fishing for the UK as support. Assuming that physical disturbance by demersal fishing enhances sedimentary carbon recycling, the logical sites for such MPAs and fisheries exclusion zones will be the accumulation areas - Skagerrak and Norwegian Trough. It would be interesting to know what the swept area ratio in these deep-water environments actually is and whether there have been monitoring activities (underwater video) in the fisheries sector to establish the extent of sediment reworking there. From the data on composition of OC in the depocenters, de Haas (1997; thesis) concludes that this OC is very recalcitrant - will it be further mineralised at all? Bakker and Helder (1993) showed that oxygen fluxes in the Skagerrak were not related to the total organic carbon (TOC) content of the sediments, and that apparently only fresh organic carbon from sinking primary production was mineralised. This suggests that the old carbon derived from

Printer-friendly version

Discussion paper 
lateral transport across the large submarine catchment is unreactive. An interesting ancillary question is, whether (and if so, how much) a decline in (postulated) remineralision from artificial disturbance will negatively feed back on primary production and thus will reduce the amount of carbon supplied for burial.

Some additional remarks and comments keyed to line numbers: \#75: this is only a temporary uptake \# 106: erosion is an unquantified term and there is reason to believe that a substantial fraction of exhumed $\mathrm{OC}$ accumulates in recent depocenters

\#122: which grain density was assumed? \#136: water depth = distance to shore? Sedimentation rate according to Müller and Suess is relevant only for deep-sea sediments and vertical transport

\#140 ff: What use are geomorphology features beyond water depth and orbital velocities? Why not use numerical values for grain sizes (Bockelmann et al., 2017)?

\#145: There are no dated cores in several of these areas (judging from a comparison of Figures 1 and 2)

\#148: LSR is 0 in most of the area, and besides the oxygen exposure time appears to be not relevant.

\#171: Which are these? Include information of statistical weights/relevance as predictor in Table 1

\#216 ff: Are these the environmental variables explaining most of the variance? $\mathrm{O} 2$ penetration depth was estimated by mud content - is that independent of OC density? Table 1 lists many predictor variables, most of which apparently are not crucial. On the other hand, sedimentation rate is a crucial parameters, but how are grain size/Folk parameters etc. linked to sedimentation rate?

Printer-friendly version

\#221: Show loadings in a figure or table

\#243: The mode of transport by OC spiraling is important here - after what time does

Discussion paper 
the material from production sites arrive at the depocenter, and how is the material reworked on the way?

\#247: Are these parameters the dominant discriminators?

\#291 ff: This raises the interesting question on who reports -producer or storage provider?

Interactive

\#297: The difference is that OC in fjord sediments probably is autochthonous (or from land), whereas Norwegian Trough collects OC from a large submarine area

\#312: I assume that these characteristic parameters are the ones shown in Figure 6 (bathymetry, oxygen penetration depth derived from mud content, energy at the sea floor from M2 and orbital velocity)? See comments above.

\#393: There is always room for improving the data base and suggestions are certainly valid. But when most samples are sands with $<0.2 \mathrm{wt} . \% \mathrm{OC}$, a standardisation of methods (which effectively has been done in the past on various occasions for the analytical steps) will not change the general conclusions. In the de Haas thesis available on the internet (Mededelingen van de Faculteit Aardwetenschappen Universiteit Utrecht No. 155: Transport, preservation and accumulation of organic carbon in the North Sea), there is information on the delta $13 \mathrm{C}$ of $\mathrm{OC}$ and $\mathrm{C} / \mathrm{N}$ ratios. \#395: Again - who is credited for sequestration of allochthonous carbon in the Norwegian trench? Those who produce the carbon (in their EEZ's), or those who store it in their EEZ's? Productivity is highest in the southern, non-depositional sectors of the North Sea. The best way to enhance sequestration potential is to increase productivity - probably by enhancing eutrophication.

Table 1: Add a measure of statistical weight Table 2: Reference needed in the caption Fig. 1: The upper bound of the color scale $(51 \mathrm{~m})$ appears to wrong. How were depositional areas selected? What is the diagonal white line from Denmark to the southern tip of Norway? Fig. 6: Are the parameters presented here as box-and-whisker

Printer-friendly version

Discussion paper 
plots the ones that are dominant, or why were they chosen (see comment above)? Fig.

Interactive comment on Biogeosciences Discuss., https://doi.org/10.5194/bg-2020-352, 2020. 